\title{
Small Solid Propellant Launch Vehicle Mixed Design Optimization Approach
}

\author{
Fredy Marcell Villanueva¹, He Linshu¹, Xu Dajun¹
}

\begin{abstract}
For a small country with limited research budget and lack of advanced space technology, it is imperative to find new approaches for the development of low-cost launch vehicles (LV), which is, among all possibilities, an interesting option for rapid access to space, focused on integration of acquired components complemented with indigenously developed subsystems. This approach requires the cooperation of developed countries with huge experience and knowledge in LV development and operations. The main objective is to develop a small three stage solid propellant LV capable of delivering a payload of $100 \mathrm{~kg}$ to a circular low earth orbit of $600 \mathrm{~km}$ altitude, with the first and second stage solid rocket motors (SRM] hypothetically acquired from different countries and the third one designed and produced domestically in accordance with the production and technological capability. This approach provides main advantages such as: reduction in total time to access the space and to master the basic knowledge of launch operations. For this purpose, an integer continuous genetic algorithm global optimization method was selected and implemented, the SRM characteristics of the first and second stage were considered as integer variables, whereas the design variables of the third stage SRM and the trajectory variable were considered as continuous. A multi discipline feasible (MDF) framework was implemented along with the propulsion, aerodynamic, mass and trajectory models. Despite their particular characteristics and constraints, the results show highly acceptable values, and the approach proved to be reliable for conceptual design level.
\end{abstract}

KEYWORDS: Launch vehicle, Mixed design optimization, Solid propellant.

\section{INTRODUCTION}

The last decade may be characterized by an increased number of small satellites delivered into the low earth orbit (LEO), and this tendency will be dominant in the coming years.

Small satellites have a reduced manufacturing cost, and are relatively easy to operate and maintain. Furthermore, the miniaturization of technology makes possible its delivery into space by using small cost effective launch vehicles (LV).

Small countries generally have a limited research budget oriented to space technology development, however, nowadays it is possible to deliver a small satellite into orbit with a reasonable budget, considering the cooperation with technologically more advanced countries.

This research was focused on finding a way to have rapid access into space and to master the basic knowledge of space development and operations. In such a way, several options had been analyzed, among them the most suitable alternative in terms of economic investment and development time resulted in a small solid propellant LV with mixed design configuration, involving a strong cooperation with different countries.

The strategy considered here prioritizes the technology integration over expensive and time consuming new development, this means that complex and advanced devices were acquired and complemented with indigenous manufactured devices using available resources and technology.

As a result, a three stage solid propellant $\mathrm{LV}$ was configured, where the first and second stage solid rocket motors (SRM) were acquired from different providers, complemented with a locally developed third stage SRM, which was designed and optimized to accomplish the specific mission.

\footnotetext{
三 1.School of Astronautics - Beihang University - Beijing - China

Author for correspondence: Fredy Marcell Villanueva | Beihang University | School of Astronautics | Haidian District, 37 Xueyuan Road - New Main Building, B923 | Beijing 100191 - China | Email: marcell385@ yahoo.com

Received: 02/13/2014|Accepted: 08/15/2014
} 
In our research, a mixed integer continuous variables genetic algorithm (GA) method has been used in order to optimize the overall configuration of the LV.

\section{LAUNCH VEHICLE MODEL}

\section{LAUNCH VEHICLE DEFINITION}

A small three stage solid propellant LV in tandem configuration is considered for this research. The mission is to deliver a $100 \mathrm{~kg}$ payload to a circular LEO of $600 \mathrm{~km}$ of altitude. The payload volume requirements and the instrument module weight were specified beforehand in mission definition analysis and are shown in Table 1.

Table 1. Launch Vehicle data.

\begin{tabular}{|c|c|c|}
\hline Variables & Units & Value \\
\hline Payload & $\mathrm{kg}$ & 100 \\
\hline Fairing mass & $\mathrm{kg}$ & 50 \\
\hline Instrument module & $\mathrm{kg}$ & 50 \\
\hline Payload deployment module & $\mathrm{kg}$ & 50 \\
\hline
\end{tabular}

\section{CONSIDERED SOLID ROCKET MOTORS}

The considered SRM are listed in the Table 2 and were selected based on the variety of design characteristics. However, it is possible to add additional parameters such as cost, availability, technology complexity, country of origin among others.

\section{PROPULSION ANALYSIS}

The propulsion analysis has been conducted for all three stages of the LV, using the classical approach presented in Sutton and Biblarz (2001) and He (2004a; 2004b). For the third stage SRM, a detailed analysis was conducted, considering the properties of the propellant. In this analysis, the burning surface is considered constant by introducing a grain geometry shape coefficient, $k_{\mathrm{s}}$, the burning surface of the grain $S_{b}$ can be calculated as:

$S_{b}=k_{s} D_{m} L_{m}$

where, $L_{m}$ is the rocket motor cylindrical length and $D_{m}$ the diameter.

The burning time $t_{b}$, grain mass $m_{g n}$, and mass flow rate $\dot{m}_{g n}$ of the grain are calculated as:

$m_{g n}=\frac{\pi}{4} \rho_{g n} \eta_{v} \lambda_{g n} D_{m}^{3}$

Table 2. Selected solid rocket motors.

\begin{tabular}{|c|c|c|c|c|c|c|c|c|c|}
\hline & SRM & $\begin{array}{c}\text { Grain } \\
\text { mass } \\
{[\mathrm{kg}]}\end{array}$ & $\begin{array}{c}\text { SRM } \\
\text { mass } \\
{[\mathrm{kg}]}\end{array}$ & $\begin{array}{c}\text { Diameter } \\
\text { [m] }\end{array}$ & $\begin{array}{l}\text { Length } \\
\text { [m] }\end{array}$ & $\begin{array}{c}\text { Specific } \\
\text { impulse } \\
\text { (N.s/kg] }\end{array}$ & $\begin{array}{c}\text { Burn } \\
\text { time } \\
\text { [s] }\end{array}$ & $\begin{array}{c}\text { Mass } \\
\text { flow } \\
{[\mathrm{kg} / \mathrm{s}]}\end{array}$ & $\begin{array}{c}\text { Thrust } \\
\text { [N] }\end{array}$ \\
\hline \multirow{4}{*}{ Stage1 } & 11 & 18400 & 20791 & 1990 & 4.80 & 2364 & 65 & 283.08 & 669194 \\
\hline & 12 & 15000 & 16779 & 1390 & 7.25 & 2314 & 74 & 202.70 & 469054 \\
\hline & 13 & 9950 & 11281 & 1390 & 5.20 & 2280 & 62 & 160.48 & 365903 \\
\hline & 14 & 4530 & 5207 & 0.98 & 4.60 & 2265 & 70 & 64.71 & 146578 \\
\hline \multirow{7}{*}{ Stage2 } & 21 & 9800 & 10950 & 1990 & 3.62 & 2805 & 65 & 150.77 & 422908 \\
\hline & 22 & 5080 & 5607 & 1390 & 3.10 & 2776 & 64 & 79.38 & 220345 \\
\hline & 23 & 4138 & 4412 & 1390 & 2.86 & 2746 & 65 & 63.66 & 174815 \\
\hline & 24 & 3700 & 4190 & 1390 & 2.40 & 2754 & 68 & 54.41 & 149850 \\
\hline & 25 & 3300 & 3650 & 1390 & 2.63 & 2824 & 55 & 60.00 & 169440 \\
\hline & 26 & 1760 & 1949 & 0.98 & 1.85 & 2776 & 46 & 38.26 & 106212 \\
\hline & 27 & 650 & 719 & 0.85 & 1.50 & 2849 & 43 & 15.12 & 43066 \\
\hline
\end{tabular}


$t_{b}=\frac{\pi \eta_{v} D_{m}}{4 u k_{s}}$

$\dot{m}_{g n}=\rho_{g n} u S_{b}=\rho_{g n} u k_{s} \lambda_{g n} D_{m}{ }^{2}$

$\lambda_{g n}=\frac{L_{g n}}{D_{g n}}$

where, $u$ is the burning rate of propellant, $\rho_{g n}$ density of the grain, $L_{g n}=L_{m}+0.314 D_{m}$ length of the grain, $D_{g n}=D_{m}$ diameter of the grain, $\lambda_{g n}$ fineness ratio of the grain (grain length/diameter), and $\eta_{v}$ the grain volumetric loading fraction.

The expansion ratio $\mathcal{E}$, nozzle throat area $A_{p}$, and nozzle exit area $A_{e}$ are calculated as:

$$
\begin{aligned}
& A_{t}=\frac{\rho_{g n} u S_{b}}{\Gamma_{0} p_{c \max }} \sqrt{R_{c} T_{c}} \\
& \varepsilon=\frac{\Gamma_{0}}{\left(\frac{p_{e}}{p_{c}}\right)^{\frac{1}{k}} \sqrt{\frac{2 k}{k-1}\left[1-\left(\frac{p_{e}}{p_{c}}\right)^{k-1}\right]}}
\end{aligned}
$$

$A_{e}=A_{t} \varepsilon$

$\Gamma_{0}=\sqrt{k}\left(\frac{2}{k+1}\right)^{\frac{k+1}{2(k-1)}}$

where, $P_{c}$ is the chamber pressure, $p_{e}$ exit pressure, $R_{c}=296 \mathrm{~J} /(\mathrm{kg} \cdot \mathrm{K})$ gas constant, $T_{c}=3300 \mathrm{~K}$ temperature in the combustion chamber, $P_{c \max }=1.1 \mathrm{P}_{c}$ maximum value of chamber pressure, and $k=1.2$ the specific heat ratio of gas.

The specific impulse $I_{s p}$, and the thrust $T$ can be calculated as:

$I_{s p}=I_{s p}^{a}+\left(\frac{p_{e}}{p_{c}}\right)^{\frac{k-1}{k}} \frac{R_{c} T_{c}}{g^{2} I_{s p}^{a}}$

$T=I_{s p} \dot{m}_{g n}-p_{a} A_{e}$

where, $p_{a}$ is the atmospheric pressure, $I_{s p}^{a}$ average specific impulse, $g$ acceleration due to gravity, and $A_{e}$ the nozzle exit area.

\section{MASS ANALYSIS}

The mass analysis was conducted for the entire LV, and is represented by the following equations:
$m_{L V}=m_{01}+m_{02}+m_{03}+m_{\text {Inert }}$

$m_{03}=m_{s t}+m_{g n}$

$m_{\text {Inert }}=m_{I M}+m_{P D M}+m_{P A Y}$

where, $m_{L V}$ is the LV gross mass, $\mathrm{m}_{01}$ first stage mass, $\mathrm{m}_{02}$ second stage mass, $m_{03}$ third stage solid rocket mass, $m_{I M}$ instrument module mass, $m_{P D M}$ payload deployment module mass, $m_{P A Y}$ payload mass, and $m_{s t}$ the structural mass of the third stage SRM.

$\mathrm{He}$ (2004a; 2004b) provided a methodology and a detailed calculation of the third stage SRM structural mass. This design consisted in a classical metallic case made of high strength steel, ethylene propylene diene monomer (EPDM) for chamber insulation, and carbon phenolic for the nozzle.

\section{AERODYNAMIC ANALYSIS}

The aerodynamic coefficients were estimated using the Missile DATCOM 1997 digital (Blake, 1998). This software is easy to use and implemented, and accurate enough for the conceptual design phase. Qazi and He (2005) and Villanueva et al. (2013) applied DATCOM in LV aerodynamics analysis. The lift and drag forces were calculated using the following relations:

$L=C_{L} q S_{\text {ref }}$

$D=C_{D} q S_{\text {ref }}$

where, $q$ is the dynamic pressure, $D$ drag force, $L$ lift force, $S_{\text {ref }}$ vehicle reference area, $C_{L}$ lift coefficient, and $C_{D}$ the drag coefficient.

The aerodynamic coefficients were calculated repeatedly for each LV configuration, the selected Mach ranged from 0 to 8 and the angle of attack from -8 to +1 degrees.

\section{TRAJECTORY ANALYSIS}

The trajectory analysis considers a 3 degree of freedom (3DOF) model, which has been modeled in SIMULINK (Zipfel, 2007; Fleeman, 2001). The previously calculated aerodynamic coefficients, the mass and the propulsion are the input parameters. In order to obtain a quick result, a $2 \mathrm{D}$ coordinate system was adopted, the LV flies as a point mass in a non rotating earth model. Figure 1 illustrates the forces acting on a LV and below a set of governing equations of motion (Xiao, 2001). The LV is flying in an inertial reference coordinate system XOY, with 


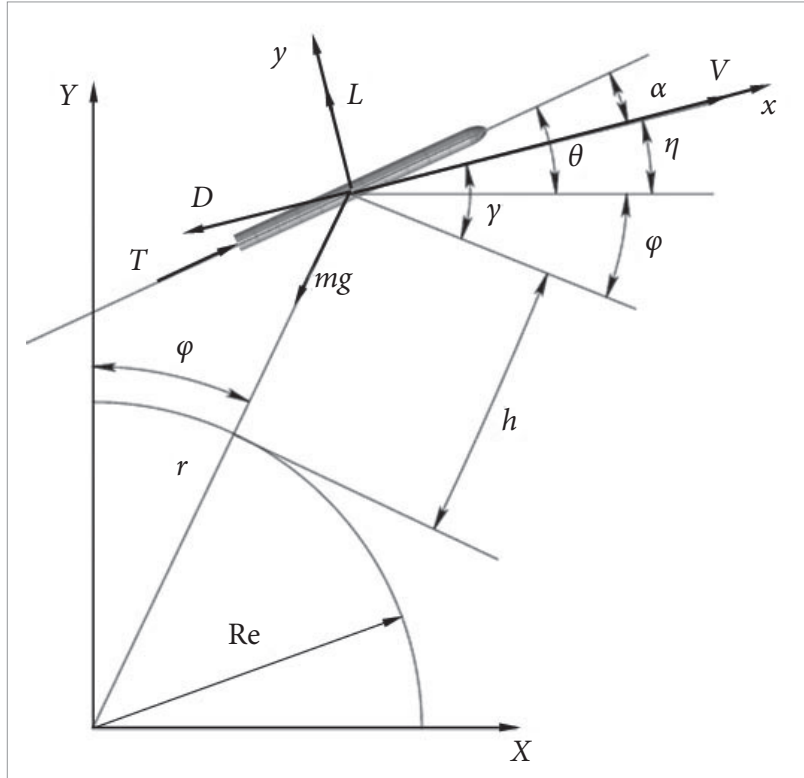

Figure 1. Forces acting on a launch vehicle.

its origin located in the center of the earth. Furthermore, all forces applied to the LV were considered in relation to the body centered velocity coordinate systems xoy as shown in Fig. 1.

$\frac{d V}{d t}=\frac{T \cos \alpha-D}{m}-g \sin \gamma$

$\frac{d \gamma}{d t}=\frac{T \sin \alpha+L}{m V}-\frac{g \cos \gamma}{V}+\frac{V \cos \gamma}{r}$

$\frac{d h}{d t}=V \sin \gamma$

$\frac{d \varphi}{d t}=\frac{V \cos \gamma}{r}$

$\alpha=\theta+\varphi-\gamma$

$\frac{d m}{d t}=-\frac{T}{I_{s p}}$

$\alpha=\alpha_{\text {prog }}(t)$

where, $V$ is the velocity, $m$ vehicle mass, $\theta$ pitch angle, $\eta$ trajectory angle, $\gamma$ flight path angle, $\varphi$ range angle, $h$ height above ground, $\alpha$ angle of attack, and $\alpha_{\text {prog }}(t)$ is the programmed angle of attack.

The axial and normal overload coefficients ensure the integrity of the LV in all phases of flight, and were calculated in a body centered velocity coordinate systems (xoy), as follows:

$n_{x}=\frac{T+L \sin \alpha-D \cos \alpha}{m g} \leq n_{x \max }$
$n_{y}=\frac{T \sin \alpha+L}{m g} \leq n_{y \max }$

The thrust to weight ratio gives an important value to evaluate the liftoff characteristics of the LV:

$v=\frac{T}{m g}$

The density variation with altitude can be calculated as:

$\rho=\rho_{0} e^{(-h / \beta)}$

The gravity varies with altitude and can be represented as:

$g=\frac{\mu}{\left(R_{e}+h\right)^{2}}$

where, $\rho_{0}$ is the sea level density, $R_{e}$ radius of earth, $\beta$ density scale height, and $\mu$ the earth gravitational parameter.

The mission requires to deliver the payload to an altitude $h_{f}$ with a circular orbital insertion velocity $V_{f}$.

$V_{f}=\sqrt{\frac{\mu}{h_{f}+R_{e}}}$

\section{TRAJECTORY PHASES}

The trajectory of the $\mathrm{LV}$ can be described as a composition of several phases, as presented by $\mathrm{He}$ (2004a), Qazi and He (2005) and Villanueva et al. (2013). For the present research, the trajectory was sectioned in seven phases, as shown in Fig. 2. Each phase has a specific flight characteristic as described next:

- Vertical launch phase: This phase starts from the time of ignition of the first stage SRM until the end of vertical flight time $t_{v}\left(t_{v}=t_{1}\right.$ in Fig. 3), during this time the LV flies vertically with a flight path angle equal to 90 degrees.

- Pitch over phase: During this phase, the LV maneuver with a negative angle of attack until the transonic velocity is reached. In this point, the angle of attack should approaches zero degrees.

- Powered first stage phase: This phase lasts until the end of the burning time of the first stage SRM. The angle of attack should be kept at zero during the stage separation process.

- Coasting phase 1: The LV flies with no thrust until the second stage ignites.

- Powered second stage phase: The duration of this phase starts with the ignition of the second stage SRM and is equal to its burning time. 
- Coasting phase 2: This phase is characterized by a prolonged ballistic free flight approaching the target altitude.

- Kick phase: This phase starts with the ignition of the third stage SRM until the insertion altitude at the required orbital velocity and flight path angle.

\section{FLIGHT PROGRAM FORMULATION}

The flight profile defines the performance and loads acting on the LV Consequently, its selection should be integrated in the optimization process. Figure 3 explains the variation of the angle of attack during the pitch over phase (He, 2004a; Xiao, 2001):

$$
\begin{aligned}
& \alpha_{\text {prog }}(t)=-\alpha_{\max } \sin ^{2} f(t) \\
& f(t)=\frac{\pi\left(t-t_{1}\right)}{a_{m}\left(t_{2}-t\right)+\left(t-t_{1}\right)} \\
& a_{m}=\frac{t_{a}-t_{1}}{t_{2}-t_{a}}
\end{aligned}
$$

where, $\alpha_{\max }$ is the maximum angle of attack, $a_{m}$ launch maneuver variable, $t_{a}$ time corresponding to maximum angle of attack, $t$ time of flight, and $t_{1}$ the time of start of pitch over phase, coincident in value with time $t_{v}$.

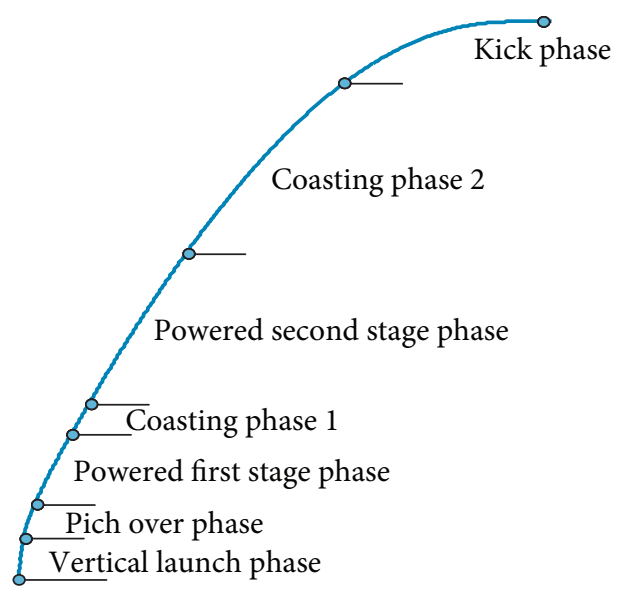

Figure 2. Trajectory phases of launch vehicle.

\section{DESIGN OPTIMIZATION PROBLEM}

\section{OBJECTIVE FUNCTION}

There can be different objective functions for LV optimization problem, such as minimization of the LV cost, which can be obtained knowing the cost of the first and second stage SRMs and the development cost of the third stage, and also the minimization of the development time, knowing the availability of the first and second stage SRM and the development time of the third stage SRM. However, this analysis considers the minimization of the gross launch mass $\left(\mathrm{m}_{\mathrm{LV}}\right)$. The mathematical description of design objective is as follows:

$\min m_{L V}=f(X)$

$g_{j}(X) \leq 0$

$h_{k}(X)=0$

$X_{l b} \leq X_{i} \leq X_{u b}$

where, $g_{j}$ is the inequality constraints, $h_{k}$ the equality constraints, $X$ the set of variables, $X_{l b}$ the lower bound of variables and $X_{u b}$ the upper bound of variables.

\section{DESIGN VARIABLES}

The design variables are composed from integer (first and second stage SRMs), and continuous third stage SRM and trajectory variables. They are listed in Table 3 and can be represented as:

$$
\begin{aligned}
& X=\left[X_{S R M}, X_{S R M 3}, X_{\text {Trajectory }}\right] \\
& X_{S R M}=\left[\mathrm{srm}_{1}, \mathrm{srm}_{2}\right]
\end{aligned}
$$

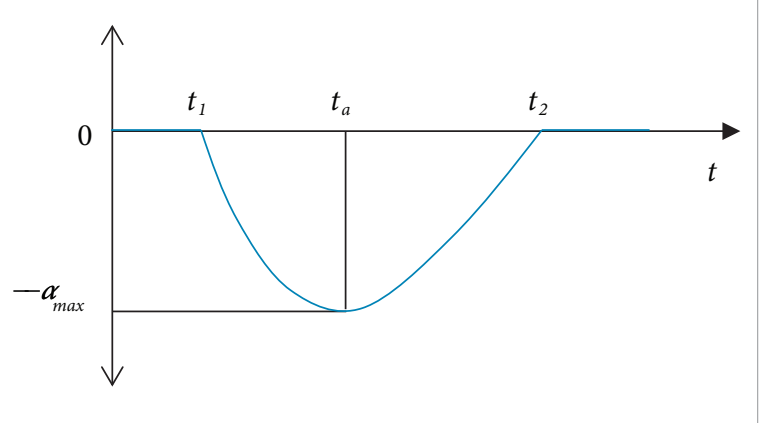

Figure 3. Pitch over ascent phase of launch vehicle. 
$X_{S R M 3}=\left[L_{m 3}, D_{m 3}, p_{c 3}, p_{e 3}, k_{s 3}, u_{3}, \rho_{g n 3}\right]$

$X_{\text {Trajectory }}=\left[t_{v}, t_{m}, t_{c 1}, t_{c 2}, \alpha_{\max }, a_{m}\right]$

\section{DESIGN CONSTRAINTS}

The selections of constraints were oriented in order to satisfy the mission, to prevent any failure during flight, and to consider the limitation of the third stage manufacturing technology. They are listed in Table 4:

\section{OPTIMIZATION STRATEGY}

\section{INTEGER CONTINUOUS OPTIMIZATION APPROACH}

The particularity of our problem deals with integer and continuous variables simultaneously. The selection of SRM type for first and second stages were considered as integer variables.
Meanwhile, the trajectory and design parameters of the third stage SRM were considered as continuous.

Several engineering applications of mixed integer continuous optimization approach were presented by Haupt et al. (2009), Faustino et al. (2006), as well as detailed explanation in Yeniay (2005) and Gantovnik et al. (2005).

Garfield and Allen (1995) used integer optimization applied to the configuration of LVs, Johnson (2002) conducted a screening process of booster for hypersonic vehicles, Calabro et al. (2002) presented the optimization of the propulsion for multistage LVs, and Bhatnagar et al. (2012) solved the mass distribution problem under restrictive condition.

Hartfield et al. (2004) have shown the application of GA in finding the global optimum in ramjet propulsion. Bayley and Hartfield (2007) used GA for LV multidisciplinary design optimization with emphasis on minimum cost.

GA has been effectively applied to solve the problem of liquid propellant based LV (Riddle et al. 2007), as well as
Table 3. Design variables.

\begin{tabular}{|c|c|c|c|}
\hline & Variables & Symbol & Units \\
\hline $\mathrm{X} 1$ & Stage 1 & $\mathrm{srm}_{1}$ & \\
\hline $\mathrm{X} 2$ & Stage 2 & $\mathrm{srm}_{2}$ & \\
\hline $\mathrm{X} 3$ & $\begin{array}{l}\text { Rocket motor cylindrical } \\
\text { length }\end{array}$ & $L_{m 3}$ & $\mathrm{~m}$ \\
\hline $\mathrm{X} 4$ & Rocket motor diameter & $D_{m 3}$ & $\mathrm{~m}$ \\
\hline $\mathrm{X} 5$ & Chamber pressure & $P_{c 3}$ & $\mathrm{~Pa}$ \\
\hline X6 & Nozzle exit pressure & $P_{e 3}$ & $\mathrm{~Pa}$ \\
\hline $\mathrm{X} 7$ & Coefficient of grain shape & $k_{s 3}$ & \\
\hline $\mathrm{X} 8$ & Grain burning rate & $u_{3}$ & $\mathrm{~m} / \mathrm{s}$ \\
\hline X9 & Grain density & $\rho_{g n 3}$ & $\mathrm{~kg} / \mathrm{m}^{3}$ \\
\hline $\mathrm{X} 10$ & Vertical flight time & $t_{v}$ & s \\
\hline $\mathrm{X} 11$ & Time to pitch over & $t_{m}$ & s \\
\hline $\mathrm{X} 12$ & $\begin{array}{c}\text { Coasting time } 1 \text { (between } 1^{\text {st }} \\
\text { and } 2^{\text {nd }} \text { stage) }\end{array}$ & $t_{c 1}$ & $\mathrm{~s}$ \\
\hline $\mathrm{X} 13$ & $\begin{array}{c}\text { Coasting time } 2 \text { ( between } \\
2^{\text {nd }} \text { and } 3^{\text {rd }} \text { stage) }\end{array}$ & $t_{c 2}$ & $S$ \\
\hline $\mathrm{X} 14$ & $\begin{array}{c}\text { Maximum angle of attack } \\
\text { (absolute) }\end{array}$ & $\alpha_{\max }$ & deg \\
\hline $\mathrm{X} 15$ & Launch maneuver variable & $a_{m}$ & \\
\hline
\end{tabular}

Table 4. Design constraints.

\begin{tabular}{|c|c|c|c|}
\hline & Constraints & Value & Units \\
\hline $\mathrm{C} 1$ & Orbit insertion velocity & $V_{f} \geq 7560$ & $\mathrm{~m} / \mathrm{s}$ \\
\hline $\mathrm{C} 2$ & Final altitude & $V_{f} \geq 600$ & $\mathrm{~km}$ \\
\hline $\mathrm{C} 3$ & Axial overload & $n_{x} \leq 14$ & \\
\hline $\mathrm{C} 4$ & Normal overload & $n_{y} \leq 2$ & \\
\hline $\mathrm{C} 5$ & $\begin{array}{l}\text { Maximum dynamic } \\
\text { pressure }\end{array}$ & $q_{\max } \leq 85$ & $\mathrm{kPa}$ \\
\hline C6 & $\begin{array}{l}\text { Angle of attack } \\
(0.8 \leq \mathrm{M} \leq 1.3)\end{array}$ & $\alpha=0$ & deg \\
\hline $\mathrm{C} 7$ & Orbit insertion angle & $\gamma=0 \pm 0.2$ & deg \\
\hline $\mathrm{C} 8$ & Rocket motor diameter & $D_{m 1} \geq D_{m 2}$ & $\mathrm{~m}$ \\
\hline C9 & Rocket motor mass & $m_{S R M 1} \geq m_{S R M 2}$ & $\mathrm{~kg}$ \\
\hline $\mathrm{C} 10$ & Total LV length & $L_{L V} \leq 18$ & $\mathrm{~m}$ \\
\hline $\mathrm{C} 11$ & Grain fineness & $\lambda_{g n 3}<2$ & \\
\hline $\mathrm{C} 12$ & Thrust to weight ratio & $v_{3} \geq 1.8$ & \\
\hline $\mathrm{C} 13$ & Nozzle exit diameter & $d_{e 3} \leq 0.9 D_{m 3}$ & $\mathrm{~m}$ \\
\hline $\mathrm{C} 14$ & Burning time & $t_{b 3} \leq 65$ & s \\
\hline
\end{tabular}


solid propellant LVs (Bayley et al. 2008). Rafique et al. (2009) and Goldberg (1989) provides detailed and comprehensive implementation of GA in solving complex problems.

\section{OPTIMIZATION METHOD}

The adopted and implemented GA optimization method is shown in Fig. 4, where a set of input design variables (SRM type, trajectory and third stage), as well as the lower and upper bounds, are passed to the main loop, where an initial population is randomly created. Furthermore, the selection, the crossover and the mutation operations are performed until the stopping criteria is achieved. The constraints

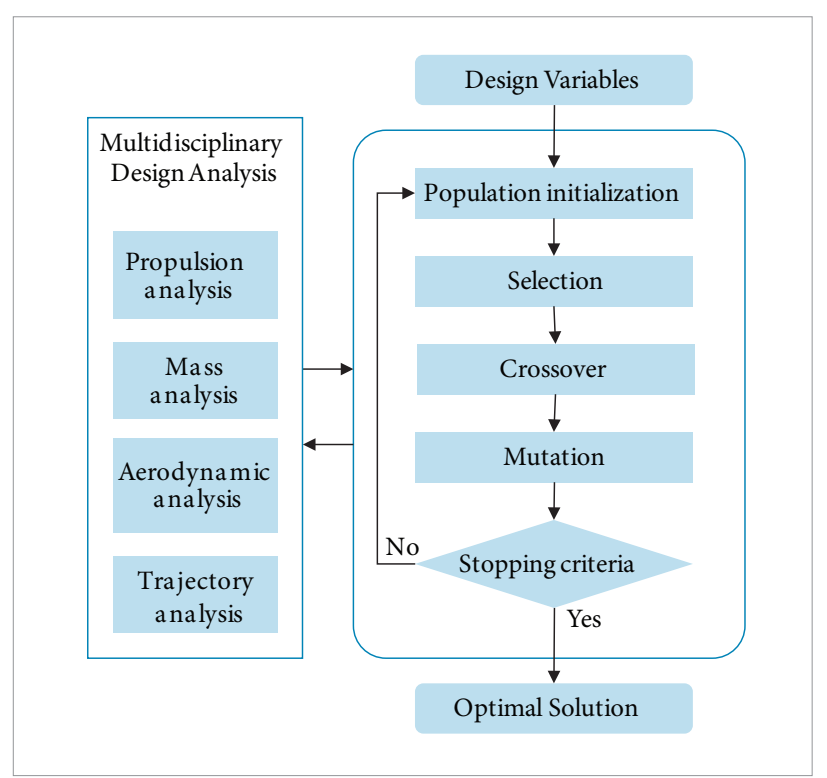

Figure 4. Genetic algorithm optimization approach. were calculated and handled by external penalty function, as presented in Deb (2000) and detailed and explained in Coello (1999) and Kramer (2010). At each routine, the propulsion, mass, aerodynamics and trajectory analysis were performed.

The main characteristics of GA are presented in Table 5.

\section{OPTIMIZATION FRAMEWORK}

The optimization framework considered for this research is based on the multi-discipline feasible (MDF) design, which allows an easy and accurate result (Qazi and He L, 2006), as shown in Fig. 5.

Table 5. Genetic algorithm characteristics.

\begin{tabular}{|c|c|}
\hline Variables & Characteristics \\
\hline Generations & 200 \\
\hline Population size & 100 \\
\hline Stopping criteria & Function tolerance 10e-6 \\
\hline Population type & Double vector \\
\hline Selection & Stochastic uniform \\
\hline Crossover & Single point pc $=0.8$ \\
\hline Mutation & Uniform pm $=0.2564$ \\
\hline Reproduction & Elite count $=2$ \\
\hline Function evaluation & 2000 \\
\hline
\end{tabular}

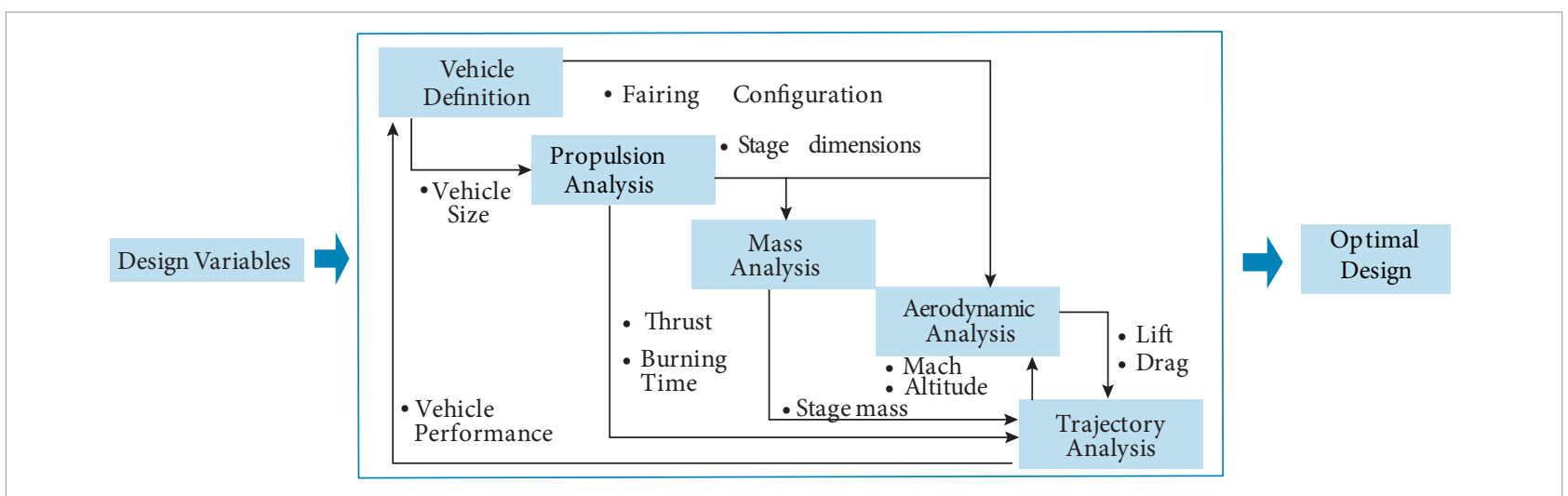

Figure 5. Multidisciplinary design optimization. 


\section{OPTIMIZATION RESULT}

The results show that the considered mixed integercontinuous GA optimization approach successfully reached the objective function. The optimized LV has a total mass of $23,530 \mathrm{~kg}$ and a $16.12 \mathrm{~m}$ of length. Table 6 shows the optimized value of variables and in Table 7 the main parameters of the LV third stage are listed.

The first and second stages SRM design type (SRM 12 and SRM 22), had been optimized and selected from Table 2. Both SRMs have the same diameter but different length. As it is represented in Fig. 6, the shroud design is configured with the same diameter as the third stage, in order to reduce the aerodynamics forces and interferences.

The performance characteristics of the LV, shown in Fig. 7, demonstrates the capability of the three stage solid propellant LV to place a small payload into the LEO orbit maintaining its main parameters inside its limit values, furthermore, the overall design configuration facilitates its launch operations.

\section{CONCLUSION}

A small three-stage solid propellant LV was configured and optimized using a mixed integer-continuous GA optimization method. The first and second stages SRM types were considered as integer variables, whereas the third stage SRM and trajectory as continuous. The main advantage of using GA relies on its independency of initial values to start the optimization, and the ability to handle integer variables. The propulsion, mass, aerodynamic and dynamic models were developed and integrated in a MDF framework.
Table 6. Optimum values of variables.

\begin{tabular}{|c|c|c|c|c|}
\hline Variables & $\begin{array}{c}\text { Lower } \\
\text { Bound }\end{array}$ & $\begin{array}{c}\text { Upper } \\
\text { Bound }\end{array}$ & $\begin{array}{c}\text { Optimized } \\
\text { Value }\end{array}$ \\
\hline $\mathrm{X} 1$ & $s r m_{1}$ & 11 & 14 & 12 \\
\hline $\mathrm{X} 2$ & $s r m_{2}$ & 21 & 27 & 22 \\
\hline $\mathrm{X} 3$ & $L_{m 3}(\mathrm{~m})$ & 0.80 & 1.20 & 0.90 \\
\hline $\mathrm{X} 4$ & $D_{m 3}(\mathrm{~m})$ & 0.80 & 1.20 & 0.83 \\
\hline $\mathrm{X} 5$ & $P_{c 3}(\mathrm{~Pa})$ & $70 \mathrm{e} 5$ & $80 \mathrm{e} 5$ & $77.42 \mathrm{e} 5$ \\
\hline $\mathrm{X} 6$ & $P_{e 3}(\mathrm{~Pa})$ & $0.05 \mathrm{e} 5$ & $0.15 \mathrm{e} 5$ & $0.133 \mathrm{e} 5$ \\
\hline $\mathrm{X} 7$ & $k_{s 3}$ & 1.10 & 1.60 & 1.14 \\
\hline $\mathrm{X} 8$ & $u_{3}(\mathrm{~m} / \mathrm{s})$ & $6.0 \mathrm{e}-3$ & $8.0 \mathrm{e}-3$ & $6.71 \mathrm{e}-3$ \\
\hline $\mathrm{X} 9$ & $\rho_{g n 3}\left(\mathrm{~kg} / \mathrm{m}^{3}\right)$ & 1650 & 1740 & 1683.1 \\
\hline $\mathrm{X} 10$ & $t_{v}(\mathrm{~s})$ & 3.0 & 6.0 & 3.01 \\
\hline $\mathrm{X} 11$ & $t_{m}(\mathrm{~s})$ & 18.0 & 25.0 & 21.57 \\
\hline $\mathrm{X} 12$ & $t_{c 1}(\mathrm{~s})$ & 2.0 & 8.0 & 4.46 \\
\hline $\mathrm{X} 13$ & $t_{c 2}(\mathrm{~s})$ & 360 & 400 & 372.61 \\
\hline $\mathrm{X} 14$ & $\alpha_{\max }(\mathrm{deg})$ & 3.0 & 6.0 & 5.731 \\
\hline $\mathrm{X} 15$ & $a_{m}$ & 0.28 & 0.42 & 0.319 \\
\hline
\end{tabular}

Table 7. Parameters of launch vehicle third stage.

\begin{tabular}{|c|c|}
\hline Parameters & Value (Units) \\
\hline Stage mass & $893.6(\mathrm{~kg})$ \\
\hline Propellant mass & $762.1(\mathrm{~kg})$ \\
\hline Stage dry mass & $131.2(\mathrm{~kg})$ \\
\hline Propellant mass fraction & 0.854 \\
\hline Average Thrust & $33.82(\mathrm{kN})$ \\
\hline Specific Impulse vac & $2702.8(\mathrm{~N} . \mathrm{s} / \mathrm{kg})$ \\
\hline Nozzle expansion ratio & 48.01 \\
\hline Thrust to weight ratio & 3.69 \\
\hline Burning time & $60.9(\mathrm{~s})$ \\
\hline
\end{tabular}

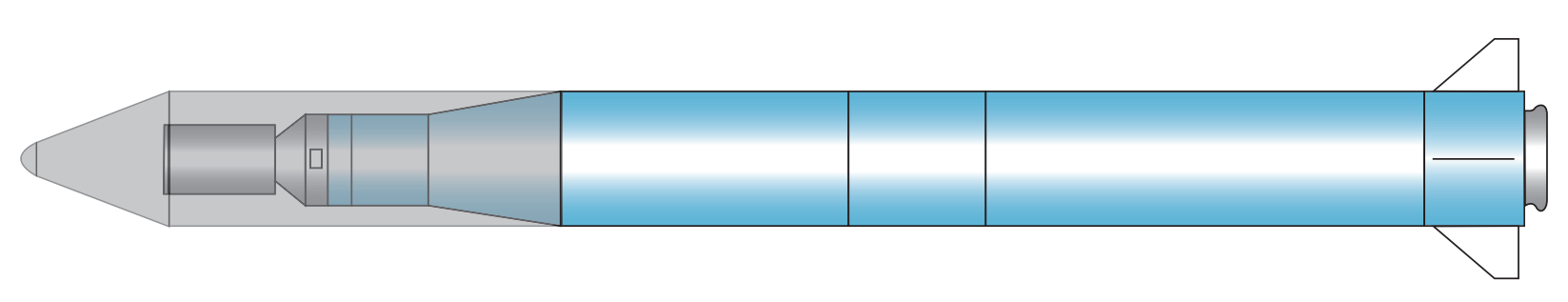

Figure 6. Optimized three stage launch vehicle. 

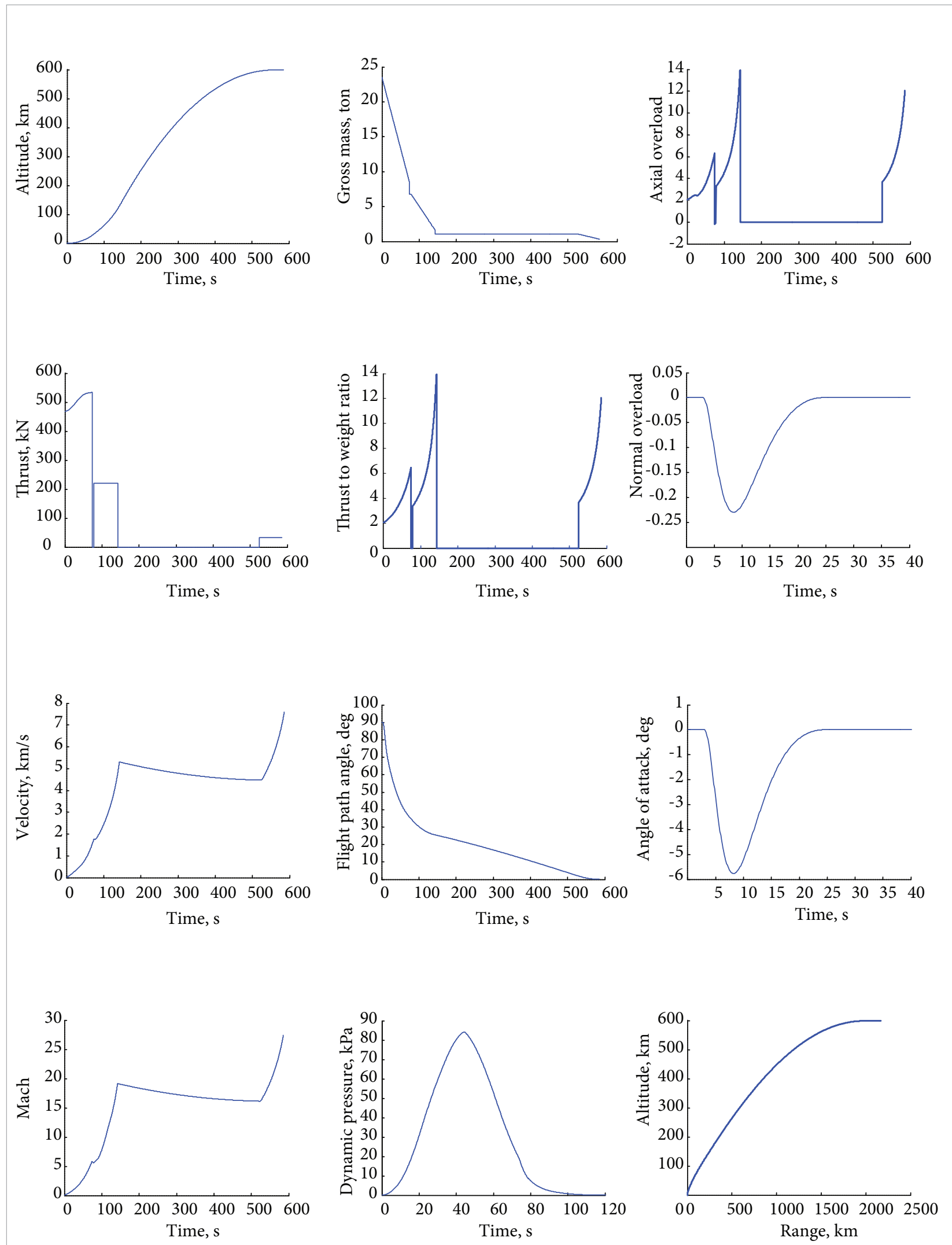

Figure 7. Performance characteristics of launch vehicle. 
An important contribution of this research is the approach in finding the best $\mathrm{LV}$ design configuration to rapid access to space with limited research budget, relied mainly on international cooperation and complemented with the indigenous aerospace manufacturing technology capability.

\section{ACKNOWLEDGMENT}

Fredy Villanueva wishes to thank Beihang University and China Scholarship Council (CSC), for their financial support.

\section{REFERENCES}

Bayley, D.J. and Hartfield, R.J., 2007, "Design Optimization of a Space Launch Vehicles for Minimum Cost Using a Genetic Algorithm", AIAA 43rd AIAA/ASME/SAE/ASEE Joint Propulsion Conference and Exhibit, AIAA 2007-5852.

Bayley, D.J., Hartfield, R.J., Burkhalter, J.E. and Jenkins R.M., 20०8, "Design Optimization of a Space Launch Vehicle Using a Genetic Algorithm", Journal of Spacecrafts and Rockets, Vol. 45, No. 4, pp. 733-740.

Bhatnagar, P., Rajan, S. and Saxena, D., 2012, "Study on Optimization Problem of Propellant Mass Distribution Under Restrictive Condition in Multistage Rocket", International Conference on Advances in Computer Applications (ICACA), No. 1, pp. 27-29.

Blake, W.B., 1998, "Missile DATCOM: User’s Manual-1997 FORTRAN 90 Revision", Wright-Patterson AFB, Oklahoma.

Calabro, M., Dufour, A. and Macaire, A., 2002, "Optimization of the Propulsion of Multistage Solid Rocket Motor Launcher", Acta Astronautica, Vol. 50, No. 4, pp. 201-208. doi: 10.1016/S00945765(01)00164-3.

Coello, C.A., 1999, "A Survey of Constraint Handling Techniques Used with Evolutionary Algorithm", Technical Report Lania-RI-99-04, Laboratorio Nacional de Informatica Avanzada, Rebamen 80, Xalapa, Veracruz 91090, Mexico.

Deb, K., 2000, "An Efficient Constraint Handling Method for Genetic Algorithm", Computer Methods in Applied Mechanics and Engineering, Vol. 186, No. 2-4, pp.311-338. doi: 10.1016/S00457825(99)00389-8.

Faustino, A.M., Judice, J.J., Ribeiro, I.M. and Neves, A.S., 2006, "An Integer Programming Model for Truss Topology Optimization", Investigação Operacional, Vol. 26, No. 1, pp. 111-127.

Fleeman, E.L., 2001, "Tactical Missile Design”, AIAA, Reston.

Gantovnik, V.B., Gurdal, Z., Watson, L.T. and Anderson-Cook, C.M. 2005, "Genetic Algorithm for Mixed Nonlinear Programming Problems Using Separate Constraint Approximations", 31st AIAA Journal, Vol. 43, No. 8, pp. 1844-1849.

Garfield, J.R. and Allen, B.D., 1995, "Screening Studies and Techniques for All-Solids Space Launch Vehicles", 31st AIAA/ASME/ SAE/ASEE Joint Propulsion Conference and Exhibit.

Goldberg, D.E., 1989, "Genetic Algorithms in Search, Optimization, and Machine Learning", Addison-Wesley.

Hartfield, R.J., Jenkins, R.M. and Burkhalter, J.E., 2004, "Ramjet Powered missile design using a genetic algorithm", 42nd AIAA Aerospace Sciences Meeting and Exhibit, AIAA 2004-0451.
Haupt, S.E., Haupt, R.I. and Young, G.S., 2011, "A Mixed Genetic Algorithm Used in Biological and Chemical Defense Applications", Software and Computing, Vol. 15, pp. 51-59. doi: 10.1007/s00500-009-0516-z.

He, L., 2004a, "Launch Vehicle Design", Beijing University of Aeronautics and Astronautics Press, Beijing.

He, L., 2004b, "Solid Ballistic Missile Design", Beijing University of Aeronautics and Astronautics Press, Beijing.

Johnson, D.B., 2002, "Screening Process for Boosters for Hypersonic Vehicles", AIAA/AAAF 11th International Space Plane and Hypersonic Systems and technologies, AIAA 2002-5218.

Kramer, 0., 2010, "A Review of Constraint-handling Techniques for Evolution Strategies", Applied Computational Intelligence and Soft Computing, Vol. 2010, Article ID 185063, pp. 11. doi: 10.1155/2010/185063

Qazi, M. and He, L., 2005, "“Rapid Trajectory Optimization Using Computational Intelligence for Guidance and Conceptual Design of Multistage Space Launch Vehicle", AIAA Guidance, Navigation, and Control Conference, AIAA 2005-6062.

Qazi, M. and He, L., 2006, "Nearly Orthogonal Sampling and Neural Network Metamodel Driven Conceptual Design of Multistage Space Launch Vehicle", Journal of Computer Aided Design, Vol. 38, No. 6, pp. 595-607. doi: 10.1016/j.cad.2006.02.001.

Rafique, A.F., He, L., Zeeshan, Q., Kamran, A., Nisar, K. and Wang Xiaowei, 2009 "Integrated System Design of Air Launched Small Space Launch Vehicle Using Genetic Algorithm", 45th AIAA/ASME/ SAE/ASEE Joint Propulsion Conference and Exhibit, AIAA-2009-5506.

Riddle, D.B., Hartfield, R.J., Burkhalter, J.E. and Jenkins, R.M., 2007, "Genetic Algorithm Optimization of Liquid Propellant Missile Systems", 45th AIAA Aerospace Sciences Meeting and Exhibit, AIAA 2007-0362.

Sutton, G.P. and Biblarz, O., 2001, "Rocket Propulsion Elements", 7th edition, Wiley-Interscience, New York.

Villanueva, F.M., He, L., Rafique, A.F. and Rahman T., 2013, "Small Launch Vehicle Trajectory Profile Optimization Using Hybrid Algorithm", International Bhurban Conference on Applied Science and Technology, Pakistan. doi: 10.1109/IBCAST.2013.6512150.

Xiao, Y., 2001, "Rocket Ballistics and Dynamics", Postgraduate Course, Beihang University.

Yeniay, 0., 2005, "Penalty Function Methods for Constrained Optimization with Genetic Algorithms", Mathematical and Computational Applications, Vol. 10, No. 1, pp. 45-56.

Zipfel, P.H., 2007, "Modelling and Simulation of Aerospace Vehicle Dynamics", AIAA, Reston. 